\title{
openheart Early follow-up after open heart valve surgery reduces healthcare costs: a propensity matched study
}

\author{
Britt Borregaard (10 , 1,2,3 Jacob Eifer Møller, ${ }^{2,4}$ Jordi Sanchez Dahl, ${ }^{2,4}$ \\ Lars Peter Schødt Riber, ${ }^{2,5}$ Selina Kikkenborg Berg, ${ }^{6,7}$ Ola Ekholm, ${ }^{8}$ \\ Marc Gjern Weiss, ${ }^{1}$ Emilie Karense Lykking, ${ }^{1}$ Kirstine Lærum Sibilitz, ${ }^{6}$ \\ Jan Sørensen ${ }^{9,10}$
}

\begin{abstract}
- Additional material is published online only. To view please visit the journal online (http://dx.doi.org/10.1136/ openhrt-2019-001122).
\end{abstract}

To cite: Borregaard B, Møller JE, Dahl JS, et al. Early follow-up after open heart valve surgery reduces healthcare costs: a propensity matched study. Open Heart 2019;6:e001122. doi:10.1136/ openhrt-2019-001122

Received 25 June 2019 Revised 15 October 2019 Accepted 30 0ctober 2019
Check for updates

(c) Author(s) (or their employer(s)) 2019. Re-use permitted under CC BY-NC. No commercial re-use. See rights and permissions. Published by BMJ.

For numbered affiliations see end of article.

Correspondence to Dr Britt Borregaard; Britt. Borregaard@rsyd.dk

\section{ABSTRACT}

Objectives The objective was to assess differences in healthcare costs within 180 days after discharge from open heart valve surgery in an intervention group receiving early, individualised and intensified follow-up compared with a historical control group.

Methods A cost-minimisation analysis comparing costs from a consecutive prospective cohort compared with a propensity matched cohort. Costs related to the intervention, hospital (outpatient visits and readmissions) and general practitioners (all contacts) were included. Data were obtained from electronic patient records and registry data. A logistic propensity model was used to identify the historical control group. Main results are presented as mean differences and $95 \%$ Cls based on bootstrapping. Results After matching, the analysis included 300 patients from the intervention group and 580 controls. The mean intervention cost was $€ 171$ (SD 79) per patient. After 180 days, the mean healthcare costs were $€ 1284$ (SD 2567) for the intervention group and $€ 2077$ (SD 4773) for the controls. The cost of the intervention group was $€ 793$ ( $p<0.001)$ less per patient. The cost differences were explained mainly by fewer readmissions, fewer overall emergency visits and fewer contacts to the general practitioner during out-of-hours in the intervention group. Conclusions The intervention consisting of early, individualised and intensified follow-up after open heart valve surgery significantly reduced the healthcare costs within 180 days after discharge.

\section{BACKGROUND}

Valvular heart disease constitutes a growing healthcare problem with a general prevalence of $2 \%-5 \%$ and a prevalence of $13 \%$ after the age of 75 years. ${ }^{1}{ }^{2}$ Heart valve surgery can be a lifesaving procedure for patients with severe symptomatic heart valve disease. ${ }^{1}$ Nevertheless, following the surgery, up to $27 \%$ of patients may require readmission within 30 days after discharge..$^{3-6}$ Besides readmissions related to complications such as atrial fibrillation, pericardial and pleural effusions, patients may also be readmitted

\section{Key questions}

What is already known about this subject?

- Readmissions after open heart valve surgery are costly, but data on costs of interventions to reduce readmissions are lacking.

What does this study add?

- Early, individualised follow-up after open heart valve surgery can reduce overall healthcare costs. Differences were explained by fewer readmissions, emergency visits and contacts to the general practitioner during out-of-hours.

How might this impact on clinical practice?

- Similar interventions to reduce readmissions after open heart valve surgery should be implemented as it reduces overall healthcare costs and improves the clinical pathway after discharge.

due to unspecified symptoms without an obvious underlying cause. ${ }^{5}$ Thus, complications and readmissions after discharge can disrupt the recovery process of the patient with risk of delaying the physical and mental recovery. ${ }^{7}$ Additionally, readmissions are a general burden to the healthcare system as they increase the overall healthcare costs as seen by Tripathi et $a l^{8}$

Only a few studies have investigated interventions aimed at reducing readmissions after open heart valve surgery. ${ }^{59}$ Lie et al have suggested that an intervention consisting of 24/7 telephone support might reduce readmissions by supporting patients to selfmanage non-urgent symptoms at home. ${ }^{9}$ In the Individualised follow-up after valve surgery (INVOLVE) study, we have recently demonstrated a reduction in readmissions among patients undergoing open heart valve surgery. ${ }^{5}$ The intervention consisted of early, individualised and intensified follow-up in a designated heart valve clinic after discharge to manage symptoms, prevent worsening of 
complications and provide support for the patient. ${ }^{5}$ Even though reducing readmissions improve care and may reduce costs, the effort to avoid readmissions may introduce new costs. Accordingly, the current study is a costminimisation analysis of the intervention compared with usual care, conducted from a healthcare perspective.

The objective was to assess differences in patient healthcare costs within 180 days after discharge from open heart valve surgery in an intervention group receiving early, individualised and intensified follow-up compared with a propensity matched historical control group.

\section{MATERIALS AND METHODS \\ Study design and scope}

Study design, participants and intervention in the INVOLVE study have previously been described. ${ }^{5}$ In brief, the study was a prospective cohort study investigating the effect of an individualised follow-up programme after open heart valve surgery on a composite endpoint of the first event of unplanned, cardiac hospital readmissions or all-cause mortality within 180 days of discharge, compared with a historical control group. The primary analysis demonstrated that the reduction in the composite measure was driven by a reduction in readmission rates, while mortality rates were unaffected. ${ }^{5}$

This analysis focuses on the 180 days postdischarge cost of intervention, hospital and general practitioners services. As the intervention aimed at cardiac causes only, non-cardiac readmissions were not included. Data from general practitioners services were included in the costanalyses as the intervention might affect how often the patients contact general practitioners postdischarge. Most commonly, the out-of-hours service includes both avoidable contacts and unavoidable contacts. For example, contacts from patients developing atrial fibrillation at home require an unavoidable contact, whereas symptom management related to the sternal wound, doubt about medication, precautions and symptom management, in general, could be avoidable contacts. These data were included to investigate possible changes during the intervention period. Use of other healthcare services such as other primary care specialists, medication and municipal were not affected during the intervention and thus assumed to be similar.

\section{Participants, setting and recruitment}

From November 2016 to November 2017, consecutive patients were enrolled in the intervention at Odense University Hospital, Denmark. The historical population was identified through the Western Denmark Heart Registry $^{10}$ as patients undergoing surgery from August 2013 to July 2016. Patients with one of the following surgical procedure codes were included (Nordic/ NOMESCO Classification of Surgical Procedures ${ }^{11}$ : Aorta (KFCA, KFMA, KFMC, KFMD), Mitral (KFKB, KFKC, KFKD, KDKW) and Tricuspidal (KFGC, KFGE).
Exclusion criteria were infective endocarditis, transfer to neurological rehabilitation from the surgical ward, transcatheter aortic valve procedures and living outside the hospital's catchment area at inclusion.

\section{Intervention and control}

Patients in both groups were referred to their general practitioner for removal of stitches 7-10 days after surgery, underwent an echocardiography 4-6 weeks after surgery as recommended by the European guidelines ${ }^{1}$ and were encouraged to participate in cardiac rehabilitation.

\section{Intervention}

The patients were included prior to surgery by a nurse, and the intervention began at discharge. The key component of the intervention was an individual risk assessment, multidisciplinary conducted. This was based on a clinical examination performed by a nurse, including a bedside focused chest ultrasound to assess pleural and pericardial effusion and a frailty test. ${ }^{5} 1213$ The results of the clinical examination were discussed with a cardiologist, who further screened the ECG and evaluated the medical treatment. All information was evaluated and summarised in an individual risk assessment with patients being grouped into a presumed high, intermediate or low risk of readmission. A further central part of the intervention was patient education performed by the nurse before discharge.

The follow-up programme was determined by the patients' risk profile, as previously outlined. ${ }^{14}$ The intervention lasted for 4 weeks after discharge, and patients were seen according to their risk profile. Thus, patients being at high risk of readmission received a closer follow-up compared with patients being at intermediate or low risk of readmission. The specific elements of the follow-up after discharge included telephone and outpatient consultations. All consultations aimed at physical and mental symptoms, possible effusion scans, patient education and a plan for further follow-up.

\section{Control group}

Follow-up of the control group consisted of routine discharge directly to the home or a local hospital and a short, unstructured telephone consultation within 7 days postdischarge performed by the nurses from the surgical ward. After discharge, the general practitioner was the primary care person.

\section{Data collection}

Demographic and clinical data, baseline

Demographics and clinical characteristics at baseline and during index admission were obtained from electronic medical records and the Western Denmark Heart Registry. ${ }^{10}$

\section{Follow-up after discharge}

Visits in outpatient clinics were captured from electronic medical records. Contact causes and whether the 
consultation was with a nurse or a physician were registered. Information on the duration of consultations (time used for staff) was recorded in minutes for the first 50 patients, and the observed mean time was assumed for all patients. The time duration of other types of consultations (eg, heart failure, arrhythmia) was based on expert assessment.

\section{Readmissions}

Readmissions were defined as an overnight hospital stay more than 24 hours after discharge from the index admission due to either a cause related to the surgery or a cardiac cause as described elsewhere. ${ }^{5}$

\section{General practitioner}

Contacts with general practitioners (both during normal opening hours and out-of-hours consultations) after discharge were obtained from The Danish National Health Service Register. ${ }^{15}$

\section{Cost data}

Unit costs were based on detailed cost calculations done in collaboration with the financial department at the hospital. Costs in general practice were obtained as fee reimbursement from The Danish National Health Service Register, adjusted to 2018-price level. The costs are presented as $2018-€(7.46 \mathrm{DKK}=1 €)$.

Costs of the intervention, staff time

Costs of the intervention included staff time spent on discharge examination (preparation time, effusion scans, frailty score, patient education and risk assessment), outpatient and telephone consultations (tables 1 and 2).
Costs of the intervention were registered according to the risk groups.

\section{Costs of the hospital services}

Costs of hospital-based contacts (hospitalisations, outpatient visits and emergency visits) were based on existing unit costs (table 2). The costs of staff salaries were estimated based on actual working hours and duration of consultations (adjusted to the actual time per patient) (see online supplementary material S1).

Furthermore, information from electronic medical records regarding echocardiography, thoracocentesis or pericardiocentesis was registered, and unit costs calculated (see online supplementary material S1).

The cost per hospital bed day (€274) was assumed as the marginal cost of readmissions days. The marginal cost of the intensive care unit (ICU) bed days was assumed at $€ 1369$. The costs of a bed day included costs of staff salary, food, medication and overhead (hospital building operation, equipment and maintenance). In the unit costs of specific outpatient procedures, staff cost was added separately.

The cost of an emergency visit due to cardiac causes including echocardiography corresponded to 0.5 hospital bed day $=€ 137$ as suggested by the financial department (table 2).

\section{Costs of contacts to general practitioners}

Resource use and costs were coded into the following groups: face-to-face or telephone consultations, other costs related to the contact and out-of-hours consultations (table 2).

Table 1 Resource use per patient in the intervention

\begin{tabular}{|c|c|c|c|c|}
\hline & \multicolumn{3}{|c|}{ The risk assessment groups of the intervention } & \multirow{2}{*}{$\begin{array}{l}\text { Total } \\
\text { intervention } \\
(n=300)\end{array}$} \\
\hline & $\begin{array}{l}\text { High risk } \\
(n=96)\end{array}$ & $\begin{array}{l}\text { Intermediate risk } \\
(n=174)\end{array}$ & $\begin{array}{l}\text { Low risk } \\
(n=30)\end{array}$ & \\
\hline \multicolumn{5}{|l|}{ Staff time to risk assessment (minutes) ${ }^{*}$, mean (SD) } \\
\hline Nurse & - & - & - & $41.3(5.1)^{\star}$ \\
\hline Cardiologist & - & - & - & $5.1(1.9)^{*}$ \\
\hline Secretary & - & - & - & $10(0.5)^{*}$ \\
\hline \multicolumn{5}{|l|}{ Telephone consultations, mean (SD) } \\
\hline \multicolumn{5}{|l|}{ Average number of consultations } \\
\hline Initiated by nurse & $1.3(1.3)$ & $1.3(1.0)$ & $1.1(0.9)$ & $1.3(1.1)$ \\
\hline Initiated by the patient & $0.6(1.1)$ & $0.4(0.7)$ & $0.6(1.4)$ & $0.5(1.0)$ \\
\hline Duration of consultations, all (minutes) ${ }^{\star} \dagger$ & - & - & - & $13.3(3.7)^{*}$ \\
\hline \multicolumn{5}{|l|}{ Nurse outpatient consultation, mean (SD) } \\
\hline Average number of consultations, per patient & $2.5(1.8) \ddagger$ & $1.9(1.2)$ & $1.3(1.3) \ddagger$ & $2.1(1.5)$ \\
\hline Duration of consultations, all (minutes) $)^{*}$ & - & - & - & $30.2(3.6)^{\star}$ \\
\hline
\end{tabular}

*The duration was recorded in minutes for the first 50 patients.

†Duration (minutes) of telephone consultations initiated by patients was not registered separately (but assumed to be equal to telephone consultations initiated by nurses).

‡Denotes statistically significant difference from intermediate-risk group ascertained by t-test. 
Table 2 Unit costs of resources related to the intervention, hospital and general practitioner services

Unit cost (2018-€)

\begin{tabular}{|c|c|}
\hline \multicolumn{2}{|l|}{ Intervention* } \\
\hline Risk assessment & 46 \\
\hline Telephone consultation & 16 \\
\hline Outpatient consultation & 48 \\
\hline \multicolumn{2}{|l|}{ Readmissions } \\
\hline Hospital bed day & 274 \\
\hline ICU-bed day & 1369 \\
\hline \multicolumn{2}{|l|}{ Procedures performed during readmissions } \\
\hline Thoracentesis & 134 \\
\hline Pericardiocentesis, parasternal approach & 129 \\
\hline Pericardiocentesis, subxiphoid, surgical & 10752 \\
\hline Emergency visits & 137 \\
\hline \multicolumn{2}{|l|}{ Outpatient procedures/consultations } \\
\hline Echocardiography & 65 \\
\hline Thoracentesis & 238 \\
\hline Pericardiocentesis, parasternal approach & 344 \\
\hline \multicolumn{2}{|l|}{ Heart failure consultations } \\
\hline Consultation with nurse & 35 \\
\hline Consultation with cardiologist & 66 \\
\hline \multicolumn{2}{|l|}{ Arrhythmia consultations } \\
\hline Consultation with nurse & 27 \\
\hline Consultation with cardiologist & 61 \\
\hline \multicolumn{2}{|l|}{ Unspecified cardiology consultations } \\
\hline Consultation with nurse & 35 \\
\hline Consultation with cardiologist & 61 \\
\hline Cardiac Surgery consultations & 61 \\
\hline \multicolumn{2}{|l|}{ Consultations with general practitioner† } \\
\hline Direct/in-person, normal opening hours & 18 \\
\hline Telephone, normal opening hours & 4 \\
\hline Out-of-hours contacts, all & 19 \\
\hline
\end{tabular}

*Based on hourly salary and multiplied with actual time used. †Other costs related to the consultations are calculated for each patient and added to the analyses.

ICU, intensive care unit.

\section{Ethics}

The study was approved by the Danish Data Protection Agency (18/19152), Danish Patient Safety Authority and conformed with the principles outlined in the Declaration of Helsinki. ${ }^{16}$ The study was registered at ClinicalTrials.gov (NCT03053778).

\section{Statistical analyses}

A propensity score matching was performed as described by Rosenbaum and Rubin. ${ }^{17}$ The multiple logistic propensity model included sex, age, acute/unplanned surgery, primary diagnosis, type of surgery, concomitant coronary artery bypass surgery, obstructive or restrictive lung disease, preoperative New York Heart Association class, EuroScore II (logistic), estimated preoperative glomerular filtration rate, permanent pacemaker prior to surgery, atrial fibrillation and body mass index. These covariates were chosen as variables assumed to be related to outcome, as suggested by Thoemmes and Kim. ${ }^{18}$ The actual matching process was performed as a 1:2 (1 intervention:2 controls) nearest-neighbour matching without replacement and a calliper width of $0.2 \mathrm{SD}^{5} 19$ The matching process and group balance were validated with descriptive statistics.

Continuous data were presented as mean and SD; categorical variables as frequencies and percentages.

Differences in healthcare utilisation were tested with the $\chi^{2}$-test. Associations between mean contacts among groups were assessed with Poisson regression and expressed with a $\mathrm{p}$ value.

The cost data were, as expected, positively skewed. ${ }^{20}$ Therefore, between-group differences were reported as 95\% CIs based on non-parametric bootstrapping (5000 replicates). ${ }^{21}$ In addition, an analysis of the differences in costs of the overall unmatched population and intervention group was performed as a sensitivity analysis.

A p value below 0.05 was considered statistically significant. SPSS 24 (IBM, Armonk, New York, USA) and Stata 13 (Stata, College Station, Texas, USA) were used to conduct the statistical analyses.

\section{RESULTS}

In total, 308 patients undergoing open heart valve surgery were included in the prospective study and 980 patients comprised the historical cohort. After propensity matching, 300 patients in the intervention group were matched to 580 historical patients (in the following mentioned as the historical control group). The matching process successfully reduced the variation between the intervention and the historical control group, creating two well-balanced groups (see online supplementary material S2). During the intervention period, aortic valve repair was introduced as a surgical option for younger patients with aortic regurgitation. Due to this, eight patients $(2 \%)$, where aortic valve repair was performed, could not be matched with historical controls and were excluded from further analyses. All 300 patients in the intervention group underwent in-hospital risk assessment and individualised follow-up.

\section{Differences in resource use}

Resource use related to the intervention was divided into resources related to the risk assessment at discharge, telephone consultations and outpatient consultations (table 1). The results reflect the intervention with patients considered being at high risk receiving more consultations compared with patients in the intermediate or low-risk group. There were few significant differences in mean resource use among patients in the different risk assessment groups (see online supplementary material S3). 
Table 3 Resource use within 180 days after discharge

\begin{tabular}{|c|c|c|c|c|c|c|}
\hline \multirow[b]{2}{*}{ Resource } & \multicolumn{4}{|c|}{ Intervention group $(n=300)$} & \multirow{2}{*}{$\begin{array}{l}\text { Historical } \\
\text { control } \\
\text { group } \\
(n=580)\end{array}$} & \multirow[b]{2}{*}{ P value* } \\
\hline & $\begin{array}{l}\text { High risk } \\
(\mathrm{n}=96)\end{array}$ & $\begin{array}{l}\text { Intermediate } \\
\text { risk } \\
(n=174)\end{array}$ & $\begin{array}{l}\text { Low risk } \\
(\mathrm{n}=30)\end{array}$ & $\begin{array}{l}\text { Total } \\
\text { intervention } \\
\text { group }\end{array}$ & & \\
\hline \multicolumn{7}{|l|}{ Cardiac readmissions, $\mathrm{n}(\%) \dagger$} \\
\hline Unplanned cardiac readmissions & $29(30)$ & $36(21)$ & $\leq 3$ & $68(23)$ & $219(38)$ & $<0.001$ \\
\hline Planned cardiac readmissions & $5(5)$ & $5(2)$ & $\leq 3$ & $11(4)$ & $31(5)$ & 0.268 \\
\hline Readmission with pericardiocentesisł & $5(5)$ & $\leq 3$ & $\leq 3$ & $9(3)$ & $40(7)$ & 0.020 \\
\hline Thoracentesis & $\leq 3$ & $\leq 3$ & $\leq 3$ & $5(2)$ & $18(3)$ & 0.205 \\
\hline Emergency room visits, $\mathrm{n}(\%) \dagger$ & $9(9)$ & $16(9)$ & $\leq 3$ & $28(9)$ & $75(13)$ & 0.116 \\
\hline \multicolumn{7}{|l|}{ Outpatient consultations/procedures, $\mathrm{n}(\%) \dagger$} \\
\hline Echocardiography & $88(92)$ & $168(97)$ & $30(100)$ & $286(95)$ & $528(91)$ & 0.022 \\
\hline Pericardiocentesis & $10(10) \S$ & $6(3)$ & $\leq 3$ & $17(6)$ & $0(0)$ & $<0.001$ \\
\hline Thoracentesis & $9(9)$ & $8(5)$ & $\leq 3$ & $17(6)$ & $31(5)$ & 0.842 \\
\hline Heart failure consultations & $8(8)$ & $14(8)$ & $\leq 3$ & $24(8)$ & $54(9)$ & 0.517 \\
\hline Arrhythmia consultations & $18(19)$ & $28(16)$ & $5(17)$ & $51(17)$ & $70(12)$ & 0.044 \\
\hline Other (unspecified) cardiology consultations & $17(18)$ & $36(21)$ & $\leq 3$ & $60(20)$ & $209(36)$ & $<0.001$ \\
\hline Cardiac surgery consultations & $7(7)$ & $7(4)$ & $\leq 3$ & $17(6)$ & $34(6)$ & 0.906 \\
\hline \multicolumn{7}{|l|}{ General practitioner, $\mathrm{n}(\%) \dagger$} \\
\hline Direct consultations, normal opening hours & $92(96)$ & $170(98)$ & $30(100)$ & $292(97)$ & $559(96)$ & 0.452 \\
\hline Telephone consultations, normal opening hours & $78(81)$ & $133(76)$ & $25(83)$ & $236(79)$ & $503(87)$ & 0.002 \\
\hline Out-of-hours consultations, all & $29(30)$ & $43(25)$ & $9(30)$ & $81(27)$ & $220(38)$ & 0.001 \\
\hline
\end{tabular}

${ }^{*} \mathrm{P}<0.05$, differences between the intervention group and the historical control group, compared using $\chi^{2}$.

$\dagger \mathrm{N}$ and $\%=$ number and proportion of patients with one or more readmission/consultation/procedure.

$\ddagger$ \#oth parasternal and subxiphoid approach.

$\S$ Denotes statistically significant difference from intermediate-risk group ascertained by $\chi^{2}$.

Compared with the historical control group, fewer patients in the intervention group experienced a readmission (23\% vs $37 \%, \mathrm{p}<0.001)$ and they were fewer days readmitted (mean days 1.66 (SD 5.43) vs 3.85 (SD 10.73), $\mathrm{p}<0.001)$. However, there was no difference in the duration of individual readmission among readmitted patients (table 3 and see online supplementary material S3). Patients in the intervention group had fewer readmissions due to pericardial effusions ( $3 \%$ vs $7 \%, \mathrm{p}=0.018)$, which was driven by 17 patients $(6 \%)$ in the intervention group who underwent pericardiocentesis in the outpatient heart valve clinic. Of those, five patients were also readmitted due to pericardial effusion. Thus, the overall number of patients undergoing pericardiocentesis after discharge was unchanged (21 patients $(7 \%)$ in the intervention group vs $40(7 \%)$ in the historical control group, $\mathrm{p}=0.889$ ). Pericardiocentesis as an outpatient procedure was only performed during the intervention period.

Specific outpatient consultations varied between the intervention and the historical control group. Although the vast majority underwent follow-up echocardiography according to guidelines in both groups, it was performed as an outpatient procedure for more patients in the intervention group ( $95 \%$ vs $91 \%, \mathrm{p}=0.022$ ). Echocardiography was performed during readmission in the remaining patients in the intervention group, where all patients had control echocardiography performed. Whether this also was the case in the control group, although likely, cannot be confirmed by the dataset. During the intervention period, more patients had consultations due to a rhythm disorder ( $17 \%$ vs $12 \%, \mathrm{p}=0.044)$, while more patients in the historical control group had outpatient consultations without specific causes $(36 \%$ vs $20 \%$ in the intervention group, $\mathrm{p}<0.001$ ) (table 3 and see online supplementary material S3).

The proportion of patients with contacts to general practitioners and visits to the emergency department were similar in the two groups, except that telephone consultations ( $79 \%$ vs $87 \%, \mathrm{p}=0.002)$ and out-of-hour contacts to general practitioner $(27 \%$ vs $38 \%, \mathrm{p}=0.001)$ were less frequent in the intervention group.

\section{Differences in costs}

The mean cost of the intervention was estimated at $€ 171$ (SD 79) per patient. The overall 180 day healthcare costs per patient were $€ 1284$ (SD 2567) for the intervention group and $€ 2077$ (SD 4773) for the historical controls. The mean saving was $€ 793 \quad(\mathrm{p}<0.001)$ per patient (table 4). The lower costs of the intervention group were caused by lower costs of cardiac readmissions, contacts to 
Table 4 Cost of the intervention and 180 days healthcare costs per patient

\begin{tabular}{|c|c|c|c|c|c|c|}
\hline \multirow[b]{3}{*}{ Costs (2018-€) } & \multicolumn{4}{|c|}{ Intervention group $(n=300)$} & \multirow{3}{*}{$\begin{array}{l}\begin{array}{l}\text { Historical } \\
\text { control group } \\
(n=580)\end{array} \\
\\
\text { Mean costs } \\
\text { per patient } \\
\text { (SD) }\end{array}$} & \multirow[b]{3}{*}{$\begin{array}{l}\text { Mean difference* } \\
\text { (bootstrapped } 95 \% \mathrm{Cl} \text { ) }\end{array}$} \\
\hline & \multicolumn{4}{|c|}{ Mean costs per patient (SD) } & & \\
\hline & $\begin{array}{l}\text { High risk } \\
(\mathrm{n}=96)\end{array}$ & $\begin{array}{l}\text { Intermediate } \\
\text { risk }(n=174)\end{array}$ & $\begin{array}{l}\text { Low risk } \\
(\mathrm{n}=30)\end{array}$ & $\begin{array}{l}\text { Total } \\
\text { intervention } \\
\text { group }\end{array}$ & & \\
\hline Intervention & $194(98)$ & $165(62)$ & $137(84)$ & $171(79)$ & - & 171 (162 to 180$)$ \\
\hline Cardiac readmissions & $630(2021)$ & $736(2930)$ & $82(251)$ & $637(2512)$ & $1540(4692)$ & $-903(-1385$ to -421$)$ \\
\hline Emergency room visits & $14(47)$ & $13(40)$ & $14(42)$ & $13(42)$ & $21(58)$ & $-8(-14$ to -1$)$ \\
\hline Outpatient consultations & $212(189)$ & $165(159)$ & $168(203)$ & $181(174)$ & $178(149)$ & $2(-21$ to 25$)$ \\
\hline General practitioner & $278(212)$ & $283(226)$ & $289(230)$ & $282(221)$ & $337(247)$ & $-55(-88$ to -24$)$ \\
\hline Total costs & $1328(2106)$ & $1362(2975)$ & $690(463)$ & $1284(3028)$ & 2077 (4773) & $-793(-1279$ to -306$)$ \\
\hline
\end{tabular}

${ }^{*}$ Comparison of mean costs per patient in the total intervention and control group, reported as mean differences and $95 \% \mathrm{Cl}$ based on nonparametric bootstrap (5000 bootstraps).

general practice and emergency visits. Costs of outpatient consultations were similar for the two groups. The sensitivity analysis for the differences in costs of the overall unmatched population demonstrated a mean difference of $€ 826$ ( $p<0.001)$ per patient (online supplementary material S4).

\section{DISCUSSION}

In this study, we investigated differences in direct patientrelated healthcare costs in the early period after heart valve surgery between patients offered early, individualised and intensified follow-up and a propensity matched historical control group. We found that the overall cost for the intervention group was significantly lower than that for the historical control group and that the additional intervention cost was outbalanced by the saving in readmissions, overall contacts with general practice and emergency visits.

This study is, to our knowledge, the first to investigate the costs of an intervention aimed at reducing readmissions after open heart valve surgery. The existing studies on costs and readmissions after heart valve procedures tend to focus on different aspects: Tripathi et al investigated differences in the costs of readmissions related to the surgery and compared costs between patients undergoing surgical aortic valve replacements with patients undergoing transcatheter aortic valve replacements (TAVR). The study was based on a national database and included $\mathrm{n}=4682$ patients. ${ }^{8}$ Also, based on the same national readmission database from the US, Kolte $e t$ al have investigated the costs of readmission, but focusing on TAVR-patients $(n=12221)$ alone. $^{22}$ Thus, the cost estimates from these studies are therefore not comparable with our cost estimates, which includes patients undergoing open heart valve surgery-based on clinical data from electronic patient records combined with register-based data. However, as demonstrated by Kolte et al, readmissions after TAVR are commonly related to postprocedure complications, why they suggest that interventions should be aimed at high-risk patients. This finding supports the need for the current intervention in the INVOLVE study. We have demonstrated how awareness of complications in combination with early and individualised follow-up can reduce readmissions after open heart valve surgery. ${ }^{5}$ In combination, similar interventions might be appropriate among patients undergoing TAVR, as suggested by Kolte. ${ }^{22}$

In our study, the costs of readmissions comprise the highest proportion of the total costs, followed by contacts to the general practitioner. All patients were referred to their general practitioner for removal of stitches. Therefore, most patients had at least one contact with general practitioners. However, the intervention group had significantly fewer telephone consultations and out-ofhour contacts to general practitioners compared with the historical control group. It has previously been demonstrated how patients undergoing heart valve surgery feel insecure and worry in the early period after discharge. ${ }^{23}$ The additional telephone consultations and out-of-hours services in the historical control group might be related to such concerns. During the intervention, patients had regular contacts to a nurse in the heart valve clinic, and they had the possibility of contacting the nurse, whenever needed. We suggest that this easy access to the heart valve clinic partly explain the lower frequency of general practitioner out-of-hours consultations.

Another finding in our study is the cost-saving related to introducing pericardiocentesis as an outpatient procedure in the intervention group. All patients in the intervention group had a focused chest ultrasound performed at discharge as part of the intervention, and patients with more than trivial pericardial effusions were managed in the early outpatient setting and seen within the first week after discharge as suggested in guidelines. ${ }^{24}$ Pericardiocentesis was performed before the patients developed tamponade, driven by imaging with significant effusion 
and clinical symptoms. ${ }^{24}$ When compared with the historical control group, the proportion of patients needing pericardiocentesis were similar, although the clinical pathway and the costs varied greatly.

Unexpectedly, the costs of outpatient consultations were not significantly different between patients receiving the intervention and patients in the historical cohort. We had expected that the introduction of the intervention would be associated with an increase in outpatient consultations, but this was not the case. This may relate to an optimised clinical pathway introduced as a further result of the intervention, as the nurses in the outpatient clinic ensured the pathway to include consultations related to specific clinical problems. In addition, echocardiography was performed by specialised cardiologists during the intervention period. Consequently, during the intervention, consultations without a specific cause were reduced while consultations due to rhythm disorders increased. In general, the multidisciplinary approach to patients undergoing heart valve surgery is known to both optimise the clinical pathway and be cost-effective. ${ }^{2526}$

Despite the significant saving introduced by the intervention, there is still potential for further optimisation of the clinical pathway after discharge, as patients still receive many contacts with healthcare professionals across different sectors, and although the readmission rates were reduced, they remain high. When investigating aspects of further optimisation of the clinical pathway after open heart valve surgery, the infrastructure in primary care and community services play an important role. ${ }^{27}$ In Denmark, the primary healthcare system commonly includes general practitioners after open heart valve surgery, which is highlighted by the high numbers of contacts with general practitioners in the postdischarge period. This knowledge should be incorporated into future studies. Similarly, the generalisability of the current study might only be relevant in similar healthcare systems; therefore, local audits of complications and patterns of readmission are appropriate before conducting a similar study or changing practise. ${ }^{27}$

\section{Strengths and limitations}

A key strength of the study was the consecutive inclusion of patients with access to complete data from electronic patient records on all patients. These data were combined with register-based information on contacts with general practitioners. In addition, information on costings was primarily based on individuallevel detailed microcosting and not a macrocosting approach (general valuation).

The study has some limitations. First, a key limitation is the non-randomised design of the study. Although we performed propensity matching to minimise bias in causal inferences, the results should still be interpreted in the context of this design. To support the reported analyses, the sensitivity analysis of the overall unmatched population demonstrated a similar cost difference among the two groups which suggests that the matching process did not exclude patients with, particularly high or low costs compared with the propensity matched population.

Second, the study was performed as a single-centre study and testing of the intervention in another clinical setting would strengthen the findings. Third, during readmissions, costings of time spent in ICU were included, but costs of reoperation or procedures other than pericardiocentesis were not. This means that due to more readmissions in the control group and therefore maybe more reoperations, the costs of the control group might be underestimated.

In conclusion, we found that the early, individualised and intensified follow-up after open heart valve surgery significantly reduced the costs within 180 days after discharge. The reduction was caused by fewer readmissions, fewer emergency visits and fewer contacts to the general practitioner during out-of-hours.

\section{Author affiliations}

${ }^{1}$ Department of Cardiothoracic and Vascular Surgery, Odense Universitetshospital, Odense, Denmark

${ }^{2}$ Faculty of Health Sciences, University of Southern Denmark, Odense, Denmark ${ }^{3}$ Open Patient Data Explorative Network, University of Southern Denmark, Odense, Denmark

${ }^{4}$ Department of Cardiology, Odense Universitetshospital, Odense, Denmark ${ }^{5}$ Department of Thoracic Surgery, Odense Universitetshospital, Odense, Denmark ${ }^{6}$ Centre for Cardiac, Vascular, Pulmonary and Infectious Diseases, Rigshospitalet, Copenhagen, Denmark

${ }^{7}$ Department of Clinical Medicin, University of Copenhagen, Copenhagen, Denmark ${ }^{8}$ National Institute of Public Health, University of Southern Denmark, Odense, Syddanmark, Denmark

${ }^{9}$ Healthcare Outcomes Research Centre (HORC), Royal College of Surgeons in Ireland Clinical Research Centre, Dublin, Ireland

${ }^{10}$ Centre for Health Economics Research (COHERE), National Institute of Public Health, University of Southern Denmark, Odense C, Denmark

Acknowledgements The authors would like to acknowledge the patients for participating and the staff at the financial department who provided supervision on resource use and unit costs.

Contributors BB, JEM and JSD designed the study. BB conducted the analyses in collaboration with JEM, OE and JSD. BB wrote the first draft of the manuscript. All authors contributed to the interpretation of data, revisions of the manuscript and approved the final version.

Funding This work was supported by Helsefonden (Grant ID; 18-B-0196), The Odense University Hospital PhD foundation, Ove William Buhl Olesen and Edith Buhl Olesen Foundation as well as Kurt Bønnelycke and Grethe Bønnelycke Foundation.

Competing interests None declared.

Patient consent for publication Obtained.

Provenance and peer review Not commissioned; externally peer reviewed.

Data availability statement Data are available on reasonable request (after approval from the Danish Data Protection Agency)

Open access This is an open access article distributed in accordance with the Creative Commons Attribution Non Commercial (CC BY-NC 4.0) license, which permits others to distribute, remix, adapt, build upon this work non-commercially, and license their derivative works on different terms, provided the original work is properly cited, appropriate credit is given, any changes made indicated, and the use is non-commercial. See: http://creativecommons.org/licenses/by-nc/4.0/.

\section{ORCID iD}

Britt Borregaard http://orcid.org/0000-0003-2702-0231 


\section{REFERENCES}

1 Baumgartner H, Falk V, Bax JJ, et al. 2017 ESC/EACTS guidelines for the management of valvular heart disease. Eur Heart $J$ 2017;38:2739-91.

2 Nkomo VT, Gardin JM, Skelton TN, et al. Burden of valvular heart diseases: a population-based study. Lancet 2006;368:1005-11.

3 Danielsen SO, Moons P, Sandven I, et al. Thirty-day readmissions in surgical and transcatheter aortic valve replacement: a systematic review and meta-analysis. Int J Cardiol 2018;268:85-91.

4 Vejpongsa $\mathrm{P}$, Bhise V, Charitakis $\mathrm{K}$, et al. Early readmissions after transcatheter and surgical aortic valve replacement. Catheter Cardiovasc Interv 2017;90:662-70.

5 Borregaard B, Dahl JS, Riber LPS, et al. Effect of early, individualised and intensified follow-up after open heart valve surgery on unplanned cardiac Hospital readmissions and all-cause mortality. Int J Cardiol 2019;289:30-6.

6 Borregaard B, Sørensen J, Ekholm O, et al. Sociodemographic, clinical and patient-reported outcomes and readmission after heart valve surgery. J Heart Valve Dis 2018;27:78-86.

7 Hansen TB, Zwisler AD, Berg SK, et al. Cardiac rehabilitation patients' perspectives on the recovery following heart valve surgery: a narrative analysis. J Adv Nurs 2016;72:1097-108.

8 Tripathi A, Flaherty MP, Abbott JD, et al. Comparison of causes and associated costs of 30-day readmission of transcatheter implantation versus surgical aortic valve replacement in the United States (a national readmission database study). Am J Cardiol 2018;122:431-9

9 Lie I, Danielsen SO, Tønnessen T, et al. Determining the impact of 24/7 phone support on hospital readmissions after aortic valve replacement surgery (the AVRre study): study protocol for a randomised controlled trial. Trials 2017;18:246.

10 Schmidt Met al. Existing data sources for clinical epidemiology: the Western Denmark heart registry. Clin Epidemiol 2010;2:137-44.

11 Committee NM-S. NOMESCO classification of surgical procedures. Copenhagen, 2011.

12 Katz S, Ford AB, Moskowitz RW, et al. Studies of illness in the aged. The index of ADL: a standardized measure of biological and psychosocial function. JAMA 1963;185:914-9.

13 Fried LP, Tangen CM, Walston J, et al. Frailty in older adults: evidence for a phenotype. J Gerontol A Biol Sci Med Sci 2001;56:M146-57.
14 Borregaard B, Dahl JS, Riber LPS, et al. Data on an intervention to reduce readmissions after open heart valve surgery. Data Brief 2019;24.

15 Sahl Andersen J, De Fine Olivarius N, Krasnik A. The Danish National health service register. Scand J Public Health 2011;39:34-7.

16 WMA. Declaration of Helsinki - ethical principles for medical research involving human subjects. Adopted by the 18th WMA General Assembly. Helsinki, Finland, 1964.

17 Rosenbaum PR, Rubin DB. The central role of the propensity score in observational studies for causal effects. Biometrika 1983;70:41-55

18 Thoemmes FJ, Kim ES. A systematic review of propensity score methods in the social sciences. Multivariate Behav Res 2011;46:90-118.

19 Austin PC. Optimal caliper widths for propensity-score matching when estimating differences in means and differences in proportions in observational studies. Pharm Stat 2011;10:150-61.

20 Briggs A, Gray A. The distribution of health care costs and their statistical analysis for economic evaluation. J Health Serv Res Policy 1998;3:233-45

21 Carpenter J, Bithell J. Bootstrap confidence intervals: when, which, what? A practical guide for medical statisticians. Stat Med 2000;19:1141-64.

22 Kolte D, Khera S, Sardar MR, et al. Thirty-Day readmissions after transcatheter aortic valve replacement in the United States: insights from the nationwide readmissions database. Circ Cardiovasc Interv 2017;10:e004472.

23 Berg SK, Zwisler A-D, Pedersen BD, et al. Patient experiences of recovery after heart valve replacement: suffering weakness, struggling to resume normality. BMC Nurs 2013;12:23.

24 Adler Y, Charron P, Imazio M, et al. 2015 ESC guidelines for the diagnosis and management of pericardial diseases. Rev Esp Cardiol 2015;68:1126.

25 Chambers JB, Prendergast B, lung B, et al. Standards defining a 'Heart Valve Centre': ESC Working Group on Valvular Heart Disease and European Association for Cardiothoracic Surgery Viewpoint. Eur $J$ Cardiothorac Surg 2017:52:418-24.

26 Lancellotti P, Rosenhek R, Pibarot P, et al. ESC Working Group on Valvular Heart Disease Position Paper--heart valve clinics: organization, structure, and experiences. Eur Heart $J$ 2013;34:1597-606.

27 Kwok CS, Balacumaraswami L, Mamas MA. Should we implement interventions to reduce readmissions in open heart valve surgery? Int J Cardiol 2019;289:50-1. 